\title{
SYNTHESIS OF 5-HYDROXYDIHYDROPYRIMIDINE DERIVATIVES AND THE INFLUENCE OF INTRAMOLECULAR HYDROGEN BONDING ON THEIR NMR PROPERTIES AND CONFORMATIONAL PREFERENCES OF THE HYDROXYL GROUP
}

\author{
AUGUSTO RIVERA*, INGRID MIRANDA-CARVAJAL AND JAIME RÍOS-MOTTA \\ Universidad Nacional de Colombia, Sede Bogotá, Facultad de Ciencias, Departamento de Química, Carrera 30 No. 45-03, Bogotá, \\ Código Postal 111321, Colombia.
}

\begin{abstract}
A series of 2,2'-(5-hydroxydihydropyrimidine-1,3(2H,4H)-diyl)bis-(methylene)-disubstitutedphenols was synthesized by using a Mannich-type reaction between 1,3-diaminopropan-2-ol, paraformaldehyde and substituted phenols. These previously unreported compounds were separated from the reaction mixture by column chromatography (CC) in highly pure form with a $29 \%-91 \%$ yield. The effect of intramolecular hydrogen bonding on the conformation of 5-hydroxyhexahydropyrimidines has been studied. Our results show that the presence of hydroxyl groups can strongly influence the stereoelectronic relationships in the six-membered heterocyclic ring.
\end{abstract}

Keywords: hexahydropyrimidine, Mannich bases, hydrogen bonding, conformational preference

\section{INTRODUCTION}

Recently, we reported a convenient general synthesis of symmetrical $\mathrm{N}, \mathrm{N}$-disubstituted hexahydropyrimidine derivatives $(\mathbf{1})$ as part of a program researching the synthesis, ${ }^{1}$ stereochemistry and reactivity of nitrogen heterocycles derived from hexahydropyrimidines. It has been noted that the dominant conformation of six-membered 1,3-diazacycles is influenced by a number of steric and electronic factors, such as the generalized anomeric effect. ${ }^{2}$ We were interested in investigating the influence of intramolecular hydrogen bonding on determining the conformations of a range of 5-hydroxyhexahydropyrimidines, namely, 2,2'-(5-hydroxydihydropyrimidine$1,3(2 \mathrm{H}, 4 \mathrm{H})$-diyl)bis-(methylene)-disubstituted phenols $(\mathbf{2 a - g})$ because replacement of a hydrogen atom in the 1,3-hexahydropyrimidine ring by a hydroxyl group may alter the stereoelectronic relationships in the heterocyclic ring. This replacement results in considerable differences in the conformational preferences due to the interaction of the hydroxyl group and the endocyclic nitrogen atoms. ${ }^{3}$ We gradually realized that the structural and mechanistic features of this class of compounds are much more complex than previously believed and defined. Using ${ }^{1} \mathrm{H}$ NMR and IR spectroscopy, Locke et al. ${ }^{2}$ demonstrated that the hydroxyl group in 5-hydroxyhexahydropyrimidine (3) is stabilized in an axial orientation by hydrogen bonding and that the N-H bonds are also stabilized in an axial orientation. Moreover, they examined the stability of the ring in 3 using the DFT (B3LYP/6-311+G**) level while quantifying the contributions and interactions of steric and electronic factors, showing that this molecule prefers the $e a$ configuration, presumably due to anomeric interactions. However, Garcías-Morales et. al. ${ }^{4}$ synthesized N,N-dibencil-1,3hexahydropyrimidines (4) with restricted conformations that reiterated the preference for the diequatorial conformation. Considering that the dominant conformation remains controversial, we planned to investigate the influence of intramolecular hydrogen bonding on determining the conformations of a range of N,N-dibenzyl-5-hydroxyhexahydropyrimidines.

The synthesis of compounds 2a-g using the same method as described above was not possible because all attempts to obtain the corresponding macrocyclic aminal $1,3,7,9,13,15,19,21$-octaazapentacyclo[ $\left[19 \cdot 3 \cdot 1 \cdot 1^{3,7} \cdot 1^{9,13} \cdot 1^{15,19}\right]$ octacosane-5,11,17,23-tetraol (5) were unsuccessful. Although hexahydropyrimidines are traditionally synthesized from condensations of alkyl diamines and aldehydes, ${ }^{5}$ in a recent study, ${ }^{6}$ Farrell et al. succeeded in the synthesis of six new hexahydropyrimidine derivatives using a three-component Mannichtype reaction involving 1,3-diaminopropane, paraformaldehyde and 2,4-substituted phenol, with excellent yields using two synthetic protocols: neat reactions in pressure flasks and reflux reactions in methanol solutions Our 2,2'-(5-hydroxydihydropyrimidine-1,3(2H,4H)-diyl)bis(methylene)disubstituted phenols (2a-g) were synthesized using the second variant of this method by combining 1 equiv of 1,3-diaminopropan-2-ol, 2 equiv of the appropriate phenol $(\mathbf{6} \mathbf{a}-\mathbf{g})$ and 3 equiv of paraformaldehyde; this mixture was refluxed in methanol for various amounts of time, as shown in Table 1. In addition to their stereochemical interest, these compounds should be of biological importance, as indicated by the derivatives with related structures

that act as analgesics, parasiticides, antifungals, and antibacterials. ${ }^{7}$

In this context, we describe the synthesis of compounds 2a-g, and we discuss the influence of hydrogen bonding on their NMR properties and conformational preferences.<smiles>[R]c1ccc(CN2CCCN(Cc3cc([R])ccc3O)C2)c(O)c1</smiles>

1<smiles>OC1CNCNC1</smiles>

Scheme 1. The chemical structures of compounds 1-5

\section{RESULTS AND DISCUSSION}

We began our study by examining the potential conversion of 1,3-diaminopropan-2-ol to the corresponding macrocyclic polyaminal $1,3,7,9,13,15,19,21$-octaazapentacyclo $\quad\left[19 \cdot 3 \cdot 1 \cdot 1^{3,7} \cdot 1^{1,13} \cdot 1^{15,19}\right]$ octacosane5,11,17,23-tetraol (5), but all attempts to synthesize this compound failed. The absence of $\mathbf{5}$ among the reaction products is most likely due to thermodynamic factors, which hinder the transformations into the macrocyclic (5). In accordance with the literature data,, 8 these intramolecular cyclizations are limiting in the condensation reaction between some 1,3-propanediamines and formaldehyde

Then, a brief survey of reaction conditions revealed that the best results were obtained through a one-pot synthetic route using an alcohol solution of 1,3-diaminopropan-2-ol, phenol and formalin or paraformaldehyde as a 
formaldehyde source to give 2a in moderate yield after $48 \mathrm{~h}$. Our preliminary experiments revealed that the best results were achieved while using paraformaldehyde as the carbonyl source and methanol under reflux conditions. These results prompted us to explore the potential use of this method for the synthesis of a series of these compounds, which could be extended to a variety of phenol derivatives. The results are summarized in Table 1 and Scheme 2

Table 1. 2,2'-(5-hydroxydihydropyrimidine-1,3(2H,4H)-diyl)bis(methylene)-disubstituted phenol (2a-g) produced via Scheme 2.

\begin{tabular}{|c|c|c|c|c|c|}
\hline Entry & Phenol & Product & Time (h) & m.p. ${ }^{\mathbf{0}} \mathbf{C}$ & $\begin{array}{c}\text { Yield } \\
\mathbf{( \% )}\end{array}$ \\
\hline $\mathbf{1}$ & $\mathbf{6 a}$ & $\mathbf{2 a}$ & 72 & $100-102$ & 51.6 \\
\hline $\mathbf{2}$ & $\mathbf{6 b}$ & $\mathbf{2 b}$ & 12 & $119-121$ & 29.0 \\
\hline $\mathbf{3}$ & $\mathbf{6 c}$ & $\mathbf{2 c}$ & 18 & $112-114$ & 34.2 \\
\hline $\mathbf{4}$ & $\mathbf{6 d}$ & $\mathbf{2 d}$ & 1 & $180-183$ & 91.0 \\
\hline $\mathbf{5}$ & $\mathbf{6 e}$ & $\mathbf{2 e}$ & 27 & $184-185$ & 90.0 \\
\hline $\mathbf{6}$ & $\mathbf{6 f}$ & $\mathbf{2 f}$ & 51 & $174-177$ & 43.4 \\
\hline $\mathbf{7}$ & $\mathbf{6 g}$ & $\mathbf{2 g}$ & 72 & $78-80$ & 57.0 \\
\hline
\end{tabular}<smiles>NCC(O)C[18O][O-]</smiles><smiles>[R]Cc1c([R])c([R4])c(CN2CC(O)CN(Cc3c([R4])c([R])c([R])c([R])c3[R4])C2)c([R])c1O</smiles>

2a-g

$6 \mathrm{a}-\mathrm{g}$

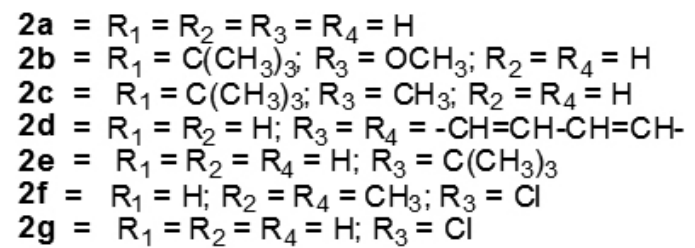

Scheme 2 Synthesis of 2,2'-(5-hydroxydihydropyrimidine-1,3(2H,4H)-diyl)bis(methylene)-disubstituted phenols (2a-g).

The use of substituted phenols bearing electron-donating and electronwithdrawing groups had no influence on the yields of the products. For example, $p$-tert-butylphenol produced the corresponding product $2 \mathbf{e}$ in good yields (Table 1, entry 5), whereas 2-tert-butyl-4-methoxyphenol provided the corresponding 1,3-bis(substituted-2-hydroxybenzyl)hexa-hydropyrimidin-5-ol 2b in $29 \%$ yield (Table 1, entry 2). $P$-chlorophenol gave the corresponding product $2 \mathrm{~g}$ in $57.0 \%$ yield; however, 4-chloro-3,5-dimethylphenol produced the corresponding aminomethylphenol $\mathbf{2 f}$ in a lower yield of $43.4 \%$, which is possibly due to steric effects (Table 1, entries 6 and 7). This method was applied to the aminomethylation of $\beta$-naphthol, which could also be used to obtain the desired product in excellent yield (Table 1, entry 4).

The formation of Mannich bases was confirmed by obtaining their IR, ${ }^{1} \mathrm{H}-\mathrm{NMR}$, mass spectra and elemental analysis results. The presence of a broad band centered at ca. $3300 \mathrm{~cm}^{-1}$ due to $\mathrm{O}-\mathrm{H}$ stretching of the phenol group confirmed that the title compounds $\mathbf{2 a - g}$ were obtained via the Mannich condensation of diamine, formaldehyde and phenols. The $\mathrm{O}-\mathrm{H}$ stretching vibration in phenol is typically observed in the $3373 \mathrm{~cm}^{-1}$ region; ${ }^{9}$ however, in the present case, the infrared spectra of the product display a medium to strong broad absorption at $3413 \mathrm{~cm}^{-1}$, which corresponds to the hydrogen bonded $\mathrm{O}-\mathrm{H}$ stretching vibration. This red shift of the $\mathrm{O}-\mathrm{H}$ stretching wavenumber is due to strong inter- or intramolecular hydrogen bonding, which is in agreement with our previous X-ray structural research in which two intramolecular hydrogen bonds were observed in the molecular structure of 1,3-bis(3-tert-butyl-2hydroxy-5-methoxybenzyl)hexahydropyrimidin-5-ol (2b) monohydrate. ${ }^{10}$ The IR spectra of the compounds also showed a characteristic absorption band with a strong intensity of the $\mathrm{C}-\mathrm{O}$ stretching of phenol, which appears at $1219 \mathrm{~cm}^{-}$ ${ }^{1}$, and an absorption band at approximately $1100 \mathrm{~cm}^{-1}$, which is characteristic of the a polarized $\mathrm{C}-\mathrm{N}$ bond. The formation of a hydrogen bond between this group and the adjacent phenolic group is responsible for the low absorption frequency, therefore confirming the formation of Mannich bases.

The ${ }^{1} \mathrm{H}$ NMR spectrum of 2a contained high-frequency resonance signals $(\delta \mathrm{H} \mathrm{7.17}, 6.98,6.85$, and 6.78) characteristic of the protons of a disubstituted phenyl group, as well as two double doublets $(\delta \mathrm{H} 3.85$ and
3.81) for the diastereotopic protons of the methylene group attached directly to the aromatic ring $\left(\mathrm{ArCH}_{2} \mathrm{~N}\right)$. These proton signals $(\delta \mathrm{H} 3.85$ and 3.81) in the HMBC experiment displayed cross-peaks with the carbon atoms of the heterocyclic systems $(\delta \mathrm{C} 72.6$ and 58.1$)$, the quaternary carbon atoms of the phenyl substituent ( $\delta \mathrm{C} 136.48$ and 157.60), and the aminalic carbon ( $\delta \mathrm{C} 57.4)$. The aminalic protons resonated as closely spaced $\mathrm{AB}$ quartets $(\delta 3.43,3.39$, $\left.{ }^{2} J_{\mathrm{AB}}=8.8 \mathrm{~Hz}\right)$ integrating for two protons. The values of $\delta\left({ }^{13} \mathrm{C}\right.$ aromatic $)$ are in the range of $157.6-116.6 \mathrm{ppm}$ and are similar to those found in other $o$-aminomethylphenols. . $^{11-12}$

To distinguish whether the hydroxyl group is attached in the axial or equatorial position of the hexahydropyrimidine ring, we analyzed the chemical shifts, spin-spin coupling constants, and the NOESY spectra. In 1,3-hexahydropyrimidines, the equatorial protons adjacent to nitrogen atoms are found to have chemical shifts downfield from their axial counterparts. ${ }^{4}$ The difference between these chemical shifts and coupling constants can be caused by the presence of secondary orbital overlap between the N-lone pairs and $\sigma^{*} \mathrm{C}-\mathrm{Hax}$ due to a preference for the antiperiplanar orientation of these vicinal hydrogens, which leads to increased electron density in the axial protons. Moreover, it is well known that in cyclohexanols, the vicinal equatorial protons are approximately $0.25-0.30 \mathrm{ppm}$ more deshielded than expected. ${ }^{13}$ This is remarkably different from the reported NMR results of 5-hydroxyhexahydropyrimidine $(3)^{2}$ which displays the ae chair conformation.

Due to the near identity of the magnitudes of the gem coupling constants $\left({ }^{2} J\right)$ and axial-axial couplings ( $\left.{ }^{3} \mathrm{Jaa}\right)$, as well as the smaller than expected proton coupling constants for ( ${ }^{3} \mathrm{Jee}$ ), in an equatorial disposition of the hydroxyl group, the observed spin-spin splitting patterns would be a doublet (for Ha) and an $\mathrm{AB}$ quartet or pseudo triplet (for $\mathrm{He}$ ). However, all vicinal protons show a multiplicity of a doublet for the most downfield signal and a broad singlet for the upfield signal but not the expected splitting patterns (Figure 1). 

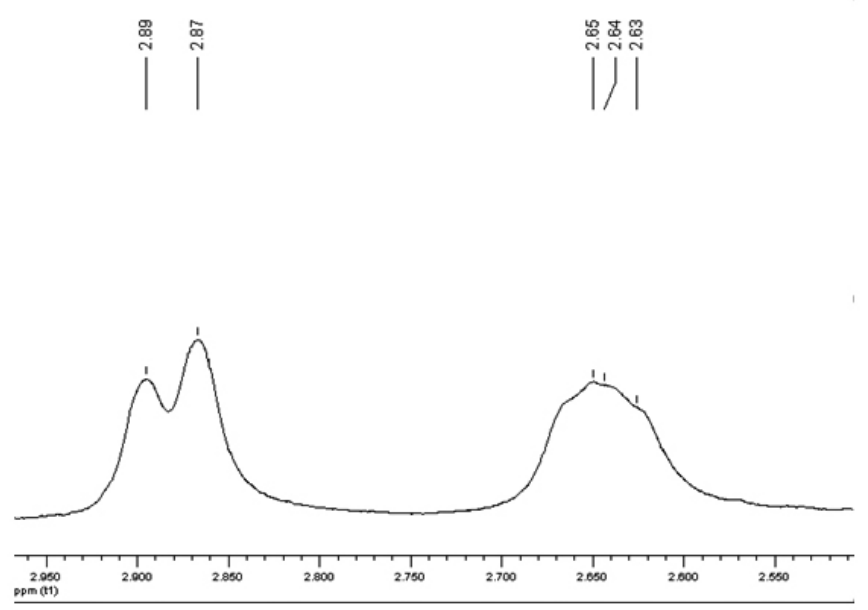

Figure $1{ }^{1} \mathrm{H}$ NMR spectrum of $\mathbf{2 a}$ in $\mathrm{CDCl}_{3}$ showed between 2.55 and $2.90 \mathrm{ppm}$

Thus, the spectra of $\mathbf{2 a - g}$ in $\mathrm{CDCl}_{3}$ were consistent with an axial $\mathrm{OH}$ group, $\left({ }^{2} J=12 \mathrm{~Hz}\right)$, presumably because the intramolecular hydrogen bond that stabilizes the axial hydroxyl group was reinforced by the presence of two phenolic hydroxyl groups. Under these conditions, the ring inversion is slow on the NMR time scale, causing separate signals; however, the couplings are not well resolved, causing the axial proton to be broader. According to the ${ }^{1} \mathrm{H}-\mathrm{NMR}$ results, with the hydroxyl group at the axial position of the hexahydropyrimidine ring, the H-5 of compounds $\mathbf{2 a - g}$ resonates at a lower field (ca. $4.00 \mathrm{ppm}$ ) compared with the H-5 (ca. 3.57 ppm) of hexahydropyrimidin-5-ol (3). ${ }^{2}$ In addition, the diastereotopic protons of the methylene group attached to the carbon bearing the hydroxyl group in $\mathbf{2 a}$ resonate at a lower field (ca. 2.65 and $2.88 \mathrm{ppm}$ ) compared with the corresponding diastereotopic protons that are more deshielded by the hydroxyl group in hexahydropyrimidin-5-ol and resonate at $2.87(\mathrm{He})$ and $3.07 \mathrm{ppm}(\mathrm{Ha})$.

A comparison of the NMR spectra of 2,2'-(dihydropyrimidine1,3(2H,4H)-diyl)bis(methylene)diphenol (1a), hexahydropyrimidin-5-o (3), and 2,2'-(5-hydroxydihydropyrimidine-1,3(2H,4H)-diyl)bis(methylene) diphenol (2a) (in $\mathrm{CDCl}_{3}$ ) (Table 2) shows that the possibility of forming $\mathrm{O}-\mathrm{H}$.... N hydrogen bonds has a locking effect on the conformation of the hexahydropyrimidine ring. However, although the differences in the chemical shifts, $\Delta$, between the axial and equatorial diastereotopic $\mathrm{CH}_{2}$ proton signals of $\mathbf{2 a}$ are nearly equal to those of $\mathbf{3}$, the anisotropic effects are different because for $\mathbf{2} \mathbf{a}$, the axial protons are upfield of the equatorial protons, but the opposite is observed for 3. It is worth noting that in most of the heterocyclic 6-membered rings, the axial protons are upfield of the equatorial protons, with some exceptions. This difference in proton shifts between $\mathbf{3}$ and $\mathbf{2 a}$ can be interpreted in terms of the difference in the inductive and stereoelectronic effects due to the presence of two phenolic hydroxyl groups.

Table 2. ${ }^{\prime} \mathrm{H}$ chemical shifts $(\delta)$ 2,2'-(dihydropyrimidine-1,3(2H,4H)-diyl)bis(methylene)diphenol (1a), 2,2'-(5-hydroxydihydropyrimidine-1,3(2H,4H)-diyl) bis(methylene)diphenol and (2a) hexahydropyrimidin-5-ol (3).

a. Ref 1

b. This study

c. Ref 2

\begin{tabular}{|c|c|c|c|c|}
\hline position & group & $\mathbf{1 a}^{\mathbf{a}}$ & $\mathbf{2 a}^{\mathbf{b}}$ & $\mathbf{3}^{\mathbf{c}}$ \\
\hline $\mathbf{2}$ & $\mathrm{CH}_{2}$ & $3.42(\mathrm{~s}, 2 \mathrm{H})$ & $\begin{array}{c}3.38(\mathrm{~d}, 1 \mathrm{H}) \\
3.43(\mathrm{~d}, 1 \mathrm{H})\left(J_{\mathrm{gem}}=8.8 \mathrm{~Hz}\right)\end{array}$ & $\begin{array}{c}3.70(\mathrm{~d}, 1 \mathrm{Hax}) \\
3.75(\mathrm{~d}, 1 \mathrm{Heq})\left(J_{\mathrm{gem}}=12.5 \mathrm{~Hz}\right)\end{array}$ \\
\hline $\mathbf{4}$ and $\mathbf{6}$ & $\mathrm{CH}_{2}$ & $2.75(\mathrm{bs}, 4 \mathrm{H})$ & $\begin{array}{c}2.65(\mathrm{bs}, 2 \mathrm{H}) \\
2.88(\mathrm{~d}, 2 \mathrm{H})\left(J_{\mathrm{gem}}=12.0 \mathrm{~Hz}\right)\end{array}$ & $\begin{array}{c}2.87(\mathrm{dd}, 2 \mathrm{Heq})\left(J_{\text {vic }}=2.9 \mathrm{and} 1 \mathrm{~Hz}\right) \\
3.07(\mathrm{dd}, 2 \mathrm{Hax})\left(J_{\text {gem }}=12.8 \mathrm{~Hz}\right)\end{array}$ \\
\hline $\mathbf{5}$ & $\mathrm{CHR}(\mathrm{H}$ or OH$)$ & $1.82(\mathrm{~m}, 2 \mathrm{H})$ & $4.04(\mathrm{~m}, 1 \mathrm{H})$ & $3.57(\mathrm{~m}, 1 \mathrm{H})$ \\
\hline $\mathbf{A r C H}_{2}$ & 4.66 & $3.68(\mathrm{~s}, 4 \mathrm{H})$ & $\begin{array}{c}3.81(\mathrm{~d}, 2 \mathrm{H}) \\
(\mathrm{d}, 2 \mathrm{H})\left(J_{\mathrm{gem}}=14.0 \mathrm{~Hz}\right)\end{array}$ & \\
\hline
\end{tabular}

An interesting observation from the ${ }^{1} \mathrm{H}$ NMR spectrum of the 2-hydroxybenzyl derivatives of 5-hydroxyhexahydropyrimidine (3) was the loss of the magnetic equivalence of the methylene hydrogen atoms of the $\mathrm{CH}_{2} \mathrm{Ph}$ group attached to the nitrogen atoms when the nitrogen atoms were alkylated. This is remarkably different from the reported NMR results of the 2,2'-(dihydropyrimidine-1,3(2H,4H)-diyldimethanediyl)diphenols $\quad(\mathbf{1})^{1}$ in which the benzylic $\mathrm{CH}_{2}$ protons and the $\mathrm{CH}_{2}$ protons in the hexahydropyrimidine ring displayed sharp singlets at room temperature. Thus, the replacement of the hydrogen atom by a hydroxyl group significantly alters the diastereotopic and magnetic equivalence of the $\mathrm{CH}_{2}$ groups. These spectral changes may be rationalized in terms of conformational changes that occur upon $\mathrm{N}$-alkylation of both of the nitrogen atoms. Because both of the phenolic hydroxyl groups are hydrogen bonded simultaneously, we assumed that the rotation around the ArC-O bond is decelerated. In fact, in $o$-aminomethylphenols (Mannich bases), the Ea was previously determined as $7.8-10.4 \mathrm{~kJ} / \mathrm{mol} .{ }^{14}$ However, for $\mathbf{1}$, the ring conformations are interconverting rapidly on the NMR time scale, whereas for 2a-g, the ring inversions are slow on the NMR time scale. The formation of an additional hydrogen bond by the incorporation of a hydroxyl group in the fifth position on the hexahydropyrimidine ring causes the heterocyclic ring to fold into an equatorial-equatorial (ee) conformation and renders all protons on $\mathrm{CH}_{2}$ diastereotopic.

\section{CONCLUSION}

In summary, the NMR results indicate that the influence of the $\mathrm{OH}$ groups of the 1,3(2H,4H)-diyl)bis(methylene)-disubstituted phenols on the NMR properties and the conformation of the hexahydropyrimidine ring is exerted through the hydrogen-bonding properties of these groups and not through steric hindrances. Replacement of the hydrogen atom by a hydroxyl group significantly alters the stereoelectronic relationships in the six-membered heterocycle.

\section{EXPERIMENTAL}

All chemical reagents and solvents were commercial products used without further purification. Thin layer chromatography (TLC) was performed on silica gel plates. Column chromatography was performed using 200-300 mesh silica gel (Hailang, Qingdao). Melting points were determined using an Electrothermal 9100 melting point apparatus and are uncorrected. FT-IR spectra were recorded in potassium bromide pellets using a Thermo Nicolet IS10 spectrophotometer. ${ }^{1} \mathrm{H}-\mathrm{NMR}$ and ${ }^{13} \mathrm{C}-\mathrm{NMR}$ spectra were recorded in $\mathrm{CDCl}_{3}$ using a Bruker Avance AV-400 MHz spectrometer operated at 400.130 $\mathrm{MHz}$ for ${ }^{1} \mathrm{H}$ and $100.634 \mathrm{MHz}$ for ${ }^{13} \mathrm{C}$. Elemental analyses $(\mathrm{C}, \mathrm{H}, \mathrm{N})$ were performed with a Thermo Scientific Flash 2000.

General Procedure for the preparation of 2,2'-(5'hydroxydihydropyrimidine-1,3(2H,4H)-diyl)bis(methylene)substituted phenols

A mixture of 1 equiv of 1,3-diaminopropan-2-ol, 3 equiv of $95 \%$ paraformaldehyde, and 2 equiv of the appropriate phenol $(\mathbf{6 a}-\mathbf{g})$ in methanol $(15 \mathrm{~mL})$ was refluxed for the time indicated in Table 1. After completion of the reaction, hexahydropyrimidine was obtained by filtration of the reaction mixture. Hexahydropyrimidine was thoroughly washed with cold ethanol and dried in vacuo.

2,2'-(5'-hydroxydihydropyrimidine-1,3(2H,4H)-diyl)bis(methylene) 
diphenol (2a): White solid, m.p. $100-102{ }^{\circ} \mathrm{C}$, yield $51.6 \%$; ${ }^{1} \mathrm{H}$ NMR $\left(\mathrm{CDCl}_{\text {, }}\right.$, $400 \mathrm{MHz}$ ): 2.65 (bs, $2 \mathrm{H}_{2} \mathrm{CH}_{2}-4 \mathrm{ax}$ and $\left.\mathrm{CH}_{2}-6 \mathrm{ax}\right), 2.88$ (d, $2 \mathrm{H}, J=11.2 \mathrm{~Hz}$, $\mathrm{CH}_{2}-4 \mathrm{eq}$ and $\left.\mathrm{CH}_{2}-6 \mathrm{eq}\right), 3.41^{2}\left(\mathrm{~d}, 1 \mathrm{H}, J=12.0 \mathrm{~Hz}, \mathrm{~N}-\mathrm{CH}_{2}-\mathrm{N}\right), 3.81(\mathrm{~d}, 2 \mathrm{H}, J$ $\left.=14.0 \mathrm{~Hz}, \mathrm{Ar}-\mathrm{CH}_{2}-\mathrm{N}\right), 3.85\left(\mathrm{~d}, 2 \mathrm{H}, J=14.0 \mathrm{~Hz}, \mathrm{Ar}-\mathrm{CH}_{2}-\mathrm{N}\right), 4.02-4.07(\mathrm{~m}$, $1 \mathrm{H}, \mathrm{H}-\mathrm{C} 5$ '), 6.78 (td, $2 \mathrm{H}, J=1.2 \mathrm{~Hz}, J=7.4 \mathrm{~Hz}, \mathrm{H}-4), 6.85$ (dd, $2 \mathrm{H}, J=1.2$, $J=8.2 \mathrm{~Hz}, \mathrm{H}-6), 6.98$ (dd, $2 \mathrm{H}, J=1.2, J=7.6 \mathrm{~Hz}, \mathrm{H}-3), 7.17$ (td, $2 \mathrm{H}, J=1.6$ $\mathrm{Hz} ; J=7.8 \mathrm{~Hz}, \mathrm{H}-5) ;{ }^{13} \mathrm{C}$ NMR (CDCl, $\left.100 \mathrm{MHz}\right): \delta 57.4\left(\mathrm{~N}-\mathrm{CH}_{2}-\mathrm{Ar}\right), 58.1$ (C4' and $\left.\mathrm{C}^{\prime}\right), 63.3\left(\mathrm{C}^{\prime}\right), 72.6\left(\mathrm{~N}-\mathrm{CH}_{2}-\mathrm{N}\right), 116.6(\mathrm{C} 2), 119.7$ ('C4), $120.5^{2}$ (C6), 129.1 (C3), 129.4 (C5), 157.6 (C1); Elem. anal. calcd. For $\mathrm{C}_{18} \mathrm{H}_{22} \mathrm{~N}_{2} \mathrm{O}_{3}$ : C $68.77 \%$; $7.05 \%$; N $8.91 \%$, O $15.27 \%$ found C $68.99 \%$; $7.65 \%$; N $7.11 \%$.

2,2'-(5'-hydroxydihydropyrimidine- $1,3(2 \mathrm{H}, 4 \mathrm{H})$-diyl)bis(methylene) bis(4-methoxy-2-tert-butylphenol) (2b): White solid, m.p. 119-121 ${ }^{\circ} \mathrm{C}$, yield $29 \%$; ${ }^{1} \mathrm{H}$ NMR $\left(\mathrm{CDCl}_{3}, 400 \mathrm{MHz}\right): \delta 1.40\left(\mathrm{~s}, 18 \mathrm{H}, \mathrm{C}\left(\mathrm{CH}_{3}\right)_{3}\right), 1.84$ (bs, $1 \mathrm{H}, \mathrm{OH}), 2.62\left(\mathrm{bs}, 2 \mathrm{H}, \mathrm{CH}_{2}-4 \mathrm{ax}\right.$ and $\left.\mathrm{CH}_{2}-6 \mathrm{ax}\right), 2.86\left(\mathrm{~d}, 2 \mathrm{H}, \mathrm{J}=11.0 \mathrm{~Hz}, \mathrm{CH}_{2}-\right.$ 4 eq and $\left.\mathrm{CH}_{2}-6 \mathrm{eq}\right), 3.42\left(\mathrm{~d}, 2 \mathrm{H}, J=10.0 \mathrm{~Hz}, \mathrm{~N}-\mathrm{CH}_{2}-\mathrm{N}\right), 3.74\left(\mathrm{~s}, 6 \mathrm{H}, \mathrm{OCH}_{3}\right.$ ), $3.76\left(\mathrm{~d}, 2 \mathrm{H}, J=14 \mathrm{~Hz}, \mathrm{Ar}-\mathrm{CH}_{2}-\mathrm{N}\right), 3.81\left(\mathrm{~d}, 2 \mathrm{H}, J=14.0 \mathrm{~Hz}, \mathrm{Ar}-\mathrm{CH}_{2}-\mathrm{N}\right)$, 4.01 (bs, 1H, H-C5'), 6.44 (d, $2 \mathrm{H}, J=2.8 \mathrm{~Hz}, \mathrm{H}-3), 6.82(\mathrm{~d}, 2 \mathrm{H} J=3.2 \mathrm{~Hz}$, $\mathrm{H}-5), 9.69(\mathrm{bs}, 2 \mathrm{H}, \mathrm{OH}) ;{ }^{13} \mathrm{C} \mathrm{NMR}\left(\mathrm{CDCl}_{1}, 100 \mathrm{MHz}\right): \delta 29.3((\mathrm{CH})), 34.8$ $\left(\underline{\mathrm{C}}\left(\mathrm{CH}_{3}\right)_{3}\right), 55.7\left(\mathrm{OCH}_{3}\right), 57.0\left(\mathrm{C}^{\prime}\right.$ ' and $\left.\mathrm{C}^{\prime}{ }^{\prime}\right), 58.5\left(\mathrm{~N}-\mathrm{CH}_{2}-\mathrm{Ar}\right), 63.1\left(\mathrm{C} 5^{\prime}\right)$, $72.6\left(\mathrm{~N}-\mathrm{CH}_{2}-\mathrm{N}\right), 111.8(\mathrm{C} 3), 113.5(\mathrm{C} 5), 121.5(\mathrm{C} 2), 138.9^{2}(\mathrm{C} 6), 150.9(\mathrm{C} 1)$, 152.6 (C4). Elem. anal. calcd. For $\mathrm{C}_{28} \mathrm{H}_{42} \mathrm{~N}_{2} \mathrm{O}_{5}: \mathrm{C} 69.14 \%$; $\mathrm{H} 8.64 \%$; $\mathrm{N} 5.76 \%$, O $16.46 \%$ found $\mathrm{C} 66.70 \%$; $\mathrm{H} 8.64 \% ; \mathrm{N} 5.77 \%$.

2,2'-(5'-hydroxydihydropyrimidine-1,3(2H,4H)-diyl)bis(methylene) bis(4-methyl-2-tert-butylphenol) (2c): White solid, m.p. $112-114^{\circ} \mathrm{C}$, yield $34.2 \%$; ${ }^{1} \mathrm{H}$ NMR $\left.\left(\mathrm{CDCl}_{3}, 400 \mathrm{MHz}\right): \delta 1.41\left(\mathrm{~s}, 18 \mathrm{H}, \mathrm{C} \mathrm{CH}_{3}\right)_{3}\right), 1.86$ (bs, $1 \mathrm{H}$, $\mathrm{OH}), 2.24\left(\mathrm{~s}, 6 \mathrm{H}, \mathrm{CH}_{3}\right), 2.62$ (bs, $2 \mathrm{H}, \mathrm{CH}_{2}-4 \mathrm{ax}$ and $\left.\mathrm{CH}_{2}-6 \mathrm{ax}\right), 2.86(\mathrm{~d}, 2 \mathrm{H}$, $J=11.0 \mathrm{~Hz}, \mathrm{CH}_{2}-4 \mathrm{eq}$ and $\left.\mathrm{CH}_{2}-6 \mathrm{eq}\right), 3.42\left(\mathrm{~d}, 2 \mathrm{H}, J=10.4 \mathrm{~Hz}, \mathrm{~N}-\mathrm{CH}_{2}-\mathrm{N}\right)$, $3.74\left(\mathrm{~d}, 2 \mathrm{H}, J=14.0 \mathrm{~Hz}, \mathrm{Ar}-\mathrm{CH}_{2}-\mathrm{N}\right), 3.81\left(\mathrm{~d}, 2 \mathrm{H}, J=14.0 \mathrm{~Hz}, \mathrm{Ar}_{-}-\mathrm{CH}_{2}-\mathrm{N}\right)$, 4.02 (bs, 1H, H-C5'), 6.68 (d, 2H $J=1.6 \mathrm{~Hz}, \mathrm{H}-3), 7.02$ (d, $2 \mathrm{H}, J=1.6 \mathrm{~Hz}$, $\mathrm{H}-5), 9.95$ (bs, $2 \mathrm{H}, \mathrm{OH}) ;{ }^{13} \mathrm{C}$ NMR $\left(\mathrm{CDCl}_{2}, 100 \mathrm{MHz}\right): \delta 20.9\left(\mathrm{CH}_{3}\right), 29.7$ $\left(\left(\mathrm{CH}_{3}\right)_{3}\right), 34.8\left(\underline{\mathrm{C}}\left(\mathrm{CH}_{3}\right)_{3}\right), 55.1\left(\mathrm{C}^{\prime}\right.$ ' and $\left.\mathrm{C}^{\prime}{ }^{\prime}\right), 58.5\left(\mathrm{~N}-\mathrm{CH}_{2}-\mathrm{Ar}\right), 63.2\left(\mathrm{C} 5^{\prime}\right)$, $72.6(\mathrm{~N}-\mathrm{CH}-\mathrm{N}), 120.7(\mathrm{C} 2), 127.3(\mathrm{C} 3), 127.7(\mathrm{C} 5), 136.9$ (C6), $140.9(\mathrm{C} 4)$, 154.2 (C1). Elem. anal. calcd. For $\mathrm{C}_{28} \mathrm{H}_{42} \mathrm{~N}_{2} \mathrm{O}_{3}$ : C 73.97\%; H 9.31\%; N 6.16\%, O $13.62 \%$, found C $71.07 \%$; $9.30 \%$; $\mathrm{N} 5.71 \%$.

2,2'-(5'-hydroxydihydropyrimidine-1,3(2H,4H)-diyl)bis(methylene) bis(2-naphthol) (2d): Rosewood solid, m.p. $180-183{ }^{\circ} \mathrm{C}$, yield $91.0 \%$; ${ }^{1} \mathrm{H}$ NMR (CDCl, $400 \mathrm{MHz}$ ): $\delta 1.29$ (bs, $1 \mathrm{H}, \mathrm{OH}), 2.83$ (bs, $2 \mathrm{H}, \mathrm{CH}_{2}-4 \mathrm{ax}$ and $\left.\mathrm{CH}_{2}-6 \mathrm{ax}\right), 2.93\left(\mathrm{~d}, 2 \mathrm{H}, J=12.0 \mathrm{~Hz}, \mathrm{CH}_{2}-4 \mathrm{eq}\right.$ and $\left.\mathrm{CH}_{2}-6 \mathrm{eq}\right), 3.56(\mathrm{~d}, 1 \mathrm{H}, J$ $\left.=10.0 \mathrm{~Hz}, \mathrm{~N}-\mathrm{CH}_{2}-\mathrm{N}\right), 3.70\left(\mathrm{~d}, 1 \mathrm{H}, J=10.0 \mathrm{~Hz}, \mathrm{~N}-\mathrm{CH}_{2}-\mathrm{N}\right), 4.10-4.14(\mathrm{~m}$, $\left.1 \mathrm{H}, \mathrm{CH}-5^{\prime}\right), 4.28\left(\mathrm{~d}, 2 \mathrm{H}, J=14.4 \mathrm{~Hz}, \mathrm{Ar}-\mathrm{CH}_{2}-\mathrm{N}\right), 4.34(\mathrm{~d}, 2 \mathrm{H}, J=14.4 \mathrm{~Hz}$, $\left.\mathrm{Ar}-\mathrm{CH}_{2}-\mathrm{N}\right), 7.14(\mathrm{~d}, 2 \mathrm{H}, J=8.8 \mathrm{~Hz}, \mathrm{H}-3), 7.30(\mathrm{td}, 2 \mathrm{H}, J=1.2 \mathrm{~Hz} ; J=7.0 \mathrm{~Hz}$; $J=8.0 \mathrm{~Hz} ; \mathrm{H}-6), 7.46$ (td, $2 \mathrm{H}, J=1.4 \mathrm{~Hz} ; J=7.0 \mathrm{~Hz} ; J=8.4 \mathrm{~Hz} ; \mathrm{H}-7), 7.70$ $(\mathrm{d}, 2 \mathrm{H}, J=8.8 \mathrm{~Hz}, \mathrm{H}-4), 7.76$ (dd, $2 \mathrm{H}, J=1.0 \mathrm{~Hz}, J=8.2 \mathrm{~Hz}, \mathrm{H}-8), 7.84(\mathrm{dd}$, $2 \mathrm{H}, J=0.6 \mathrm{~Hz}, J=8.6 \mathrm{~Hz}, \mathrm{H}-5) ;{ }^{13} \mathrm{C} \mathrm{NMR}\left(\mathrm{CDCl}_{3}, 100 \mathrm{MHz}\right): \delta 49.4\left(\mathrm{C}^{\prime}\right.$ ' and C6'), $58.0\left(\mathrm{~N}-\mathrm{CH}_{2}-\mathrm{Ar}\right), 61.4\left(\mathrm{C}^{\prime}\right), 73.5\left(\mathrm{~N}-\mathrm{CH}_{2}-\mathrm{N}\right), 113.6(\mathrm{C} 1), 118.8(\mathrm{C} 3)$, 122.9 (C8), 123.3 (C7), 126.7 (C6), 128.6 (C5), 128.8 (C4a), 129.3 (C4), 134.0 (C8a), 155.5 (C2); Elem. anal. calcd. For $\mathrm{C}_{26} \mathrm{H}_{26} \mathrm{~N}_{2} \mathrm{O}_{3}$ : C 75.36\%; $\mathrm{H}$ 6.28\%; N $6.76 \%$, O $11.47 \%$, found C $75.40 \%$; $6.34 \% ; \mathrm{N} 6.44 \%$.

2,2'-(5'-hydroxydihydropyrimidine-1,3(2H,4H)-diyl)bis(methylene) bis(4-tert-butylphenol) (2e): Pale yellow solid, $\mathrm{mp} 184-185^{\circ} \mathrm{C}$, yield $90.0 \%$; ${ }^{1} \mathrm{H}$ NMR $\left(\mathrm{CDCl}_{3}, 400 \mathrm{MHz}\right): \delta 1.26\left(\mathrm{~s}, 18 \mathrm{H}, \mathrm{C}\left(\mathrm{CH}_{3}\right)_{3}\right), 2.65\left(\mathrm{bs}, 2 \mathrm{H}, \mathrm{CH}_{2}-4 \mathrm{ax}\right.$ and $\left.\mathrm{CH}_{2}-6 \mathrm{ax}\right), 2.92\left(\mathrm{~d}, 2 \mathrm{H}, J=12.0 \mathrm{~Hz}, \mathrm{CH}_{2}-4 \mathrm{eq}\right.$ and $\left.\mathrm{CH}_{-}-6 \mathrm{eq}\right), 3.46(\mathrm{bs}, 2 \mathrm{H}$, $\left.\mathrm{N}-\mathrm{CH}_{2}-\mathrm{N}\right), 3.84$ (s, $\left.4 \mathrm{H}, \mathrm{Ar}-\mathrm{CH}_{2}-\mathrm{N}\right), 4.04-4.09\left(\mathrm{~m}, 1 \mathrm{H}, \mathrm{H}-5^{\prime}\right), 6.79(\mathrm{~d}, 2 \mathrm{H} J$ $=8.4 \mathrm{~Hz}, \mathrm{H}-6), 6.97(\mathrm{~d}, 2 \mathrm{H} J=2.4 \mathrm{~Hz}, \mathrm{H}-3), 7.19(\mathrm{dd}, 2 \mathrm{H}, J=2.4 \mathrm{~Hz}, J=8.4$ $\left.\mathrm{Hz} \mathrm{H}-5) ;{ }^{13} \mathrm{C} \mathrm{NMR}\left(\mathrm{CDCl}_{1}, 100 \mathrm{MHz}\right): \delta 31.4(\mathrm{CH})\right), 33.8(\mathrm{C}(\mathrm{CH})), 57.2$ (C4' and $\left.\mathrm{C}^{\prime}\right), 58.2\left(\mathrm{~N}-\mathrm{CH}_{2}-\mathrm{Ar}\right), 63.0\left(\mathrm{C}^{\prime}\right), 72.7\left(\mathrm{~N}-\mathrm{CH}_{2}-\mathrm{N}\right), 115.1(\mathrm{C} 6)$, 119.9 (C2), 126.3 (C3), 126.5 (C5), 142.9 (C4), 153.9 (C1); Elem. anal. calcd. For $\mathrm{C}_{2} \mathrm{H}_{3} \mathrm{~N}_{2} \mathrm{O}_{3}$ : C $73.20 \% ; \mathrm{H} 8.98 \%$; N 6.57\%, O $11.25 \%$ found $\mathrm{C} 72.75 \%$; H $8.93 \% ;$ N $6.45 \%$

2,2'-(5'-hydroxydihydropyrimidine-1,3(2H,4H)-diyl)bis(methylene) bis(4-chloro-3,5-dimethylphenol) (2f): White solid m.p. $174-177^{\circ} \mathrm{C}$; yield 43.4\%; ' ${ }^{1} \mathrm{H} \mathrm{NMR}\left(\mathrm{CDCl}_{3}, 400 \mathrm{MHz}\right): \delta 1.66(\mathrm{bs}, 1 \mathrm{H}, \mathrm{OH}), 2.30$ (s, $6 \mathrm{H}, \mathrm{Ar}-$ $\left.\mathrm{CH}_{3}\right), 2.31$ (s, 6H, Ar-CH ), 2.68 (bs, $2 \mathrm{H}, \mathrm{CH}-4 \mathrm{ax}$ and $\mathrm{CH}_{2}-6 \mathrm{ax}$ ), 2.82 (d, $2 \mathrm{H}, J=11.0 \mathrm{~Hz}, \mathrm{CH}_{2}-4 \mathrm{eq}$ and $\left.\mathrm{CH}_{2}-6 \mathrm{eq}\right), 3.36$ (d, $1 \mathrm{H}, J=10.0 \mathrm{~Hz}, \mathrm{~N}-\mathrm{CH}_{2}-\mathrm{N}$ ), $3.47\left(\mathrm{~d}, 1 \mathrm{H}, J=10.0 \mathrm{~Hz}, \mathrm{~N}-\mathrm{CH}_{2}-\mathrm{N}\right), 3.84\left(\mathrm{~d}, 2 \mathrm{H}, J=14.0 \mathrm{~Hz}, \mathrm{Ar}-\mathrm{CH}_{2}-\mathrm{N}\right)$, $3.90(\mathrm{~d}, 2 \mathrm{H}, J=14.0 \mathrm{~Hz}, \mathrm{Ar}-\mathrm{CH}-\mathrm{N}), 3.98-4.02(\mathrm{~m}, 1 \mathrm{H}, \mathrm{CH}-5$ '), $6.63(\mathrm{~s}$, $2 \mathrm{H}, \mathrm{H}-\mathrm{C} 6), 10.45$ (bs, $1 \mathrm{H}, \mathrm{OH}) ;{ }^{13} \mathrm{C}-\mathrm{NMR}\left(\mathrm{CDCl}_{3}, 100 \mathrm{MHz}\right): \delta 16.4(\mathrm{Ar}-$ $\left.\mathrm{CH}_{3}\right), 20.6\left(\mathrm{Ar}-\mathrm{CH}_{3}\right), 50.5\left(\mathrm{~N}-\mathrm{CH}_{2}-\mathrm{Ar}\right), 57.9\left(\mathrm{C}^{\prime}{ }^{\prime}\right.$ and $\left.\mathrm{C} 6{ }^{\prime}\right), 61,3\left(\mathrm{C}^{\prime}\right), 72.4$ $(\mathrm{N}-\mathrm{CH}-\mathrm{N}), 115.4(\mathrm{C} 6), 120.7(\mathrm{C} 2), 124.0(\mathrm{C} 4), 135.0$ (C5), 135.6 (C3), 155.2 (C1); Elem. anal. calcd. For $\mathrm{C}_{2} \mathrm{H}_{22} \mathrm{Cl}_{2} \mathrm{~N}_{2} \mathrm{O}_{3}$ : C 60.14\%; $\mathrm{H} 6.42 \%$; $\mathrm{Cl} 16.17 \%$, N $6.38 \%$, O $10.92 \%$, found C $59.97 \%$; H $6.47 \%$; N $6.38 \%$.

$\mathbf{2 , 2}$-(5'-hydroxydihydropyrimidine-1,3(2H,4H)-diyl)bis(methylene) bis(4-chlorophenol) (2g): Yellow solid mp $78-80{ }^{\circ} \mathrm{C}$; yield $57.0 \%$; ${ }^{1} \mathrm{H}$ NMR
$(\mathrm{CDCl}, 400 \mathrm{MHz}): \delta 2.73$ (bs, $2 \mathrm{H}, \mathrm{CH}-4 \mathrm{ax}$ and $\left.\mathrm{CH}_{-}-6 \mathrm{ax}\right), 2.86$ (d, $2 \mathrm{H}, J=$ $11.2 \mathrm{~Hz}, \mathrm{CH}_{2}-4 \mathrm{eq}$ and $\left.\mathrm{CH}_{2}-6 \mathrm{eq}\right), 3.30\left(\mathrm{~d}, 1 \mathrm{H}, J=10.0 \mathrm{~Hz}, \mathrm{~N}-\mathrm{CH}_{2}-\mathrm{N}\right), 3.43$ (d, $\left.1 \mathrm{H}, J=10.0 \mathrm{~Hz}, \mathrm{~N}-\mathrm{CH}_{2}-\mathrm{N}\right) 3.77$ (d, $2 \mathrm{H}, J=14.0 \mathrm{~Hz}, \mathrm{Ar}_{-}-\mathrm{CH}_{2}-\mathrm{N}$ ), 3.82 $\left(\mathrm{d}, 2 \mathrm{H}, J=14.0 \mathrm{~Hz}, \mathrm{Ar}-\mathrm{CH}_{2}-\mathrm{N}\right), 4.04-4.09\left(\mathrm{~m}, 1 \mathrm{H}, \mathrm{H}-\mathrm{C} 5^{\prime}\right), 6.78$ (d, $2 \mathrm{H}, J=$ $8.4 \mathrm{~Hz}, \mathrm{C6}), 6.96$ (d, $2 \mathrm{H}, J=2.4 \mathrm{~Hz}, \mathrm{C} 3), 7.12(\mathrm{dd}, 2 \mathrm{H}, J=2.4 \mathrm{~Hz}, J=8.6 \mathrm{~Hz}$, C5), 9.85 (bs, $1 \mathrm{H}) ;{ }^{13} \mathrm{C}-\mathrm{NMR}\left(\mathrm{CDCl}_{3}, 100 \mathrm{MHz}\right): \delta 53.4$ (C4' and $\mathrm{C} 6$ '), 58.3 $\left(\mathrm{CH}_{2}-\mathrm{Ar}\right), 61.5\left(\mathrm{C} 5^{\prime}\right), 72.5\left(\mathrm{~N}-\mathrm{CH}_{2}-\mathrm{N}\right), 116.8(\mathrm{C} 6), 122.3(\mathrm{C} 2), 125.2(\mathrm{C} 4)$, 127.6 (C3), 128.3 (C5), 155.2(C1); Elem. anal. calcd. For $\mathrm{C}_{18} \mathrm{H}_{20} \mathrm{Cl}_{2} \mathrm{~N}_{2} \mathrm{O}_{3}$ : C $56.41 \%$; H $5.26 \%$; Cl 18.50\%, N 7.31\%, found C 58.79\%; H 5.81\%; N $6.50 \%$.

\section{ACKNOWLEDGMENTS}

The authors acknowledge the financial support provided by the Dirección de Investigaciones, Bogotá (DIB), at the National University of Colombia through research project No. 28427 (QUIPU code 201010023412). IMC thanks COLCIENCIAS for a fellowship.

\section{REFERENCES}

1. A. Rivera, J. Ríos-Motta, G.P. Trujillo, D.M. Gonzalez, D. Alcazar, Synthetic Commun. 43, 791, (2013)

2. J.M. Locke, R.L. Crumbie, R. Griffith, T.D. Bailey, S. Boyd, J.D. Roberts, J. Org. Chem. 72, 4156, (2007)

3. U. Salzner, J. Org. Chem., 60, 986, (1995)

4. C. Garcías-Morales, S.H. Martínez-Salas, A. Ariza-Castolo, Tetrahedron Lett. 53, 3310, (2012)

5. J. Dale, T. Sigvartsen, Acta Chem. Scand. 45, 1064, (1991)

6. J.R. Farrell, J. Niconchuk, C.S. Higham, B.W. Bergeron, Tetrahedron Lett. 48, 8034, (2007)

7. J.A. Bisceglia, J.E. Díaz, R.A. Torres, L.R. Orelli, Tetrahedron Lett. 52, 5238, (2011)

8. T. Axenrod, J. Sun, K.K. Das, P.R. Dave, F. Forohar, M. Kaselj, N.J. Trivedi, R.D. Gilardi, J.L. Flippen-Anderson, J. Org. Chem. 65, 1200 (2000)

9. D. Lin-Vien, N.B. Colthup, W.B. Fateley, J.G. Graselli, The handbook of Infrared and Raman characteristic frequencies of organic molecules. Academic Press: Boston, 1991.

10. A. Rivera, I. Miranda-Carvajal, H.J. Osorio, J. Ríos-Motta, M. Bolte, Acta Cryst. E. 70, o687, (2014)

11. A. Rivera, J. Ríos-Motta, R. Quevedo, P. Joseph-Nathan, Rev. Colomb. Quim. 34, 105, (2005)

12. A. Rivera, G.I. Gallo, M.E. Gayón, P. Joseph-Nathan, Synth. Commun 23, 2921, (1993)

13. D. Danneels, M. Anteunis, Tetrahedron Lett. 16, 687, (1975)

14. B. Brzezinski, G.S. Denisov, N.S. Golubev, S.N. Smirnov, J, Mol. Struct. 267, 383, (1992) 